\title{
CONTRIBUIÇÕES DA PSICOLOGIA HISTÓRICO-CULTURAL PARA A PEDAGOGIA HISTÓRICO-CRÍTICA ${ }^{1}$
}

\author{
Lígia Márcia Martins ${ }^{2}$
}

\begin{abstract}
RESUMO
Esse artigo tem como objetivo apresentar elementos fundamentados na psicologia histórico-cultural reiterativos da transmissão dos conhecimentos científicos historicamente sistematizados como condição de desenvolvimento humano e função precípua da educação escolar. Nessa direção, aponta a apropriação de signos como marco decisivo na superação das bases psíquicas naturais em direção à formação de propriedades psicofísicas culturalmente instituídas, caracterizando o psiquismo como sistema interfuncional responsável pela constituição da imagem subjetiva da realidade objetiva. Em face de tais pressupostos, afirma o papel da educação escolar na formação da referida imagem, com destaque às diferenças qualitativas resultantes do ensino pautado em conceitos cotidianos $\mathrm{e}$ espontâneos e em conceitos científicos. Advoga que a defesa da qualidade dos signos disponibilizados à apropriação pela educação escolar é o ponto de intersecção central entre a psicologia histórico cultural e a pedagogia histórico-crítica.

Palavras-chave: Psicologia Histórico-Cultural; Pedagogia Histórico-Crítica; Desenvolvimento Psíquico.
\end{abstract}

\section{CONTRIBUITIONS FROM HISTORICAL-CULTURAL PSYCHOLOGY TO HISTORICAL-CRITICAL PEDAGOGY}

\begin{abstract}
This article aims to show elements based on historical-cultural psychology, which are reiterative of historically systematized scientific knowledge transmission as condition of human development and essential function of school education. In that way, it points the sign appropriation as decisive mark in the natural psychic basis overcoming towards to culturally established psychophysical properties formation, characterizing the psychism as an interfuncional system answerable for the constitution of the subjective image of objective reality. In the face of such presuppositions, it firms the role of school education in the mentioned image formation, highlighting the qualitative differences resultant of education based to quotidian and spontaneous concepts, as well as scientific ones. It pleads that the defense of sign quality offered to appropriation by school education is the main intersection point between the historical-cultural psychology and the historical-critical pedagogy.
\end{abstract}

Keywords: Historical-Cultural Psychology; Historical-Critical Pedagogy; Psychic Development.

\section{Introdução}

Visamos nesse trabalho apresentar elementos que identifiquem pressupostos da psicologia histórico-cultural e da pedagogia histórico-crítica em relação ao desenvolvimento psíquico e apropriação da cultura, naquilo que implicam a educação escolar. Intencionamos demonstrar que no cerne do preceito vigotskiano segundo o qual o desenvolvimento do psiquismo humano corresponde à formação dos comportamentos complexos culturalmente instituídos - com a formação das "funções psíquicas superiores", 
radica a afirmação do ensino sistematicamente orientado à transmissão dos conceitos científicos, tal como preconizado pela pedagogia histórico-crítica.

Para o desenvolvimento do tema em questão, colocaremos em foco três questões. As duas primeiras, mais diretamente voltadas à psicologia histórico-cultural, versam sobre a natureza social do desenvolvimento psíquico e a proposição do psiquismo como sistema interfuncional. A terceira nos conduz ao apontamento de interdependências existentes entre o desenvolvimento psíquico e os processos de apropriação de signos consubstanciados na transmissão dos conhecimentos, bem como de diferenças qualitativas resultantes do ensino pautado em conceitos cotidianos e espontâneos e em conceitos científicos.

Com base nessas proposições, defenderemos a tese segundo a qual o ponto de intersecção entre a psicologia histórico-cultural e a pedagogia histórico-crítica, para além de seus pressupostos marxistas comuns, reside na defesa intransigente da qualidade dos signos disponibilizados à apropriação por meio do ensino escolar. Essa assertiva determina a análise da natureza dos conteúdos e atividades escolares, tendo em vista que os mesmos se instituem como lastro sobre a qual se edifica o psiquismo humano e sua forma mais complexa de expressão: a consciência dos indivíduos. Por conseguinte, em face da proposição metodológica marxista segundo a qual os fenômenos devam ser captados como sínteses de múltiplas determinações, consideramos que os investimentos na formação da consciência dos indivíduos por meio da educação escolar se impõem como uma das determinações requeridas na elaboração de outro projeto de sociedade e, a esse serviço, a pedagogia histórico-crítica advoga a transmissão dos conhecimentos objetivados historicamente e consolidados pela prática social do conjunto dos homens.

\section{Natureza social do desenvolvimento psíquico}

A afirmação da natureza social do psiquismo humano marca a origem da psicologia histórico cultural, cujos proponentes foram Lev Semenovich Vigotski ${ }^{3}$, Alexander Romanovich Luria e Alexis Nikolaevich Leontiev que, na década de 1920, se uniram em torno do desafio de edificar uma base comum à psicologia, buscando numa concepção filosófica determinada - o materialismo histórico-dialético, seus princípios metodológicos fundantes.

As formulações de Karl Marx e Friedrich Engels representam, pois, o estofo filosófico a partir do qual os proponentes da psicologia histórico-cultural encontraram as possibilidades de superação dos enfoques idealistas ou materialistas mecanicistas vigentes na psicologia desde as suas origens.

Tomando o trabalho (atividade vital humana) como gênese do psiquismo complexo, Vigotski, Luria e Leontiev conferiram novos rumos às investigações psicológicas, tendo em vista a elaboração de uma teoria que superasse as inúmeras vertentes psicológicas que, grosso modo: a) desgarram o desenvolvimento psíquico de suas bases concretas, isto é, sociais e históricas; b) pressupõem a formação das estruturas psíquicas complexas como consequência natural do desenvolvimento de estruturas simples; c) preterem a existência dos fenômenos psicológicos em suas intervinculações e interdependências priorizando análises por decomposição; d) identificam o desenvolvimento psíquico com a maturação de suas bases orgânicas.

Assim, esses autores partiram da centralidade do trabalho social na constituição humana para explicar a gênese e, sobretudo, o percurso do desenvolvimento psíquico. Consideraram que foi exatamente a necessidade de melhor captar e dominar a realidade que determinou a estruturação do psiquismo como amálgama dos processos requeridos à formação da imagem subjetiva da realidade objetiva. Alinhados à concepção materialista 
dialética de conhecimento, afirmaram que a atividade que localiza o ser na realidade objetiva, ao mesmo tempo, a transforma em realidade subjetiva, em "reflexo psíquico da realidade" (LEONTIEV, 1978, p.19).

Nessa direção, o psiquismo humano desponta como unidade material e ideal expressa na subjetivação do objetivo. É material na medida em que é estrutura orgânica e é ideal posto ser o reflexo da realidade, a ideia que a representa subjetivamente. Todavia, para a psicologia histórico-cultural, não se trata de prescindir da materialidade da imagem (ideia) muito menos contrapor uma à outra (matéria e ideia). Trata-se, igualmente, de situálas no mundo material da atividade humana que inaugura uma forma especial de relação entre sujeito e objeto, isto é, uma forma de relação mediada pela consciência.

Se do ponto de partida do processo de humanização a atividade respalda-se no legado filogenético da espécie, nos processos denominados por Vygotski $(1995 ; 1997)$ como funções psíquicas elementares, no transcurso do desenvolvimento histórico instituem-se outras propriedades psicofísicas como resultados e condições do trabalho social, o que quer dizer, da existência cultural dos indivíduos. A essas propriedades o autor denominou funções psíquicas superiores.

As funções psíquicas em suas propriedades elementares (naturais) e superiores (culturais), por sua vez, fundem-se num sistema único, interfuncional, uma vez que nenhuma delas, isoladamente, se revela apta e suficiente à representação subjetiva do objeto, isto é, à estruturação da consciência. Do exposto resulta a definição históricocultural do psiquismo humano como unidade dialética matéria/ideia graças a qual se institui a imagem subjetiva da realidade objetiva por meio de um sistema interfuncional altamente complexo.

Entretanto, do ponto de vista psíquico, o que a natureza provê - e que Vigotski denominou como funções primitivas ou elementares, não distinguem, em absoluto, o homem dos demais animais superiores. Para que de fato essa distinção ocorra tais funções carecem ser superadas pelos processos superiores, requeridos à formação dos comportamentos complexos culturalmente instituídos. Ademais, essa superação não corresponde a um processo evolutivo natural e linear que avança da natureza à cultura, "do simples para o complexo", no qual cada etapa já está potencialmente incluída na antecedente. Fiel à compreensão dialética do desenvolvimento humana, o autor explicou a referida superação como resultado das contradições internas que se travam entre natureza e cultura, entre o substrato biológico e a existência social.

Opondo-se às concepções que apreendem o desenvolvimento psíquico como endógeno e naturalmente condicionado, Vygotski (1995, p. 150) postulou o que chamou de "lei genética geral do desenvolvimento psíquico", segundo a qual toda função psíquica entra em cena duas vezes, em dois planos distintos: num primeiro, como função interpessoal e interpsíquica; num segundo, como função intrapessoal, intrapsíquica. Assim posto, nada existe no plano intrapsíquico que não encontre apoio em condições objetivas de vida e, sobretudo, de educação, a quem cumpre a tarefa de promover as apropriações requeridas à vida social.

Não obstante tal proposição ainda restava, segundo Vigotski, identificar o meio, o veículo pelo qual os fenômenos sociais interpsíquicos se convertem em processos intrapsíquicos. Encontrou na internalização de signos o mecanismo fundante dessa transmutação. Os signos, na condição de representantes semióticos da cultura humana, se convertem em instrumentos psíquicos e as operações mediadas por eles, condicionantes basilares da humanização do psiquismo.

Para Vygotski (1995), a característica mais geral na expressão das funções elementares se identifica com o imediatismo da resposta comportamental à estimulação do 
ambiente. Diferentemente, nas operações mediadas, próprias às funções superiores, os signos se interpõem como estímulos de segunda ordem, rompendo a fusão imediata entre ação e estimulação que a mobiliza.

Os signos retroagem sobre o sujeito possibilitando-lhe uma estimulação autogerada, condição para o autodomínio da conduta, para o exercício intencional, voluntário, de seu próprio psiquismo. Tomando de empréstimo o postulado marxiano acerca do papel do uso de ferramentas na instituição do ato de trabalho, Vigotski afirmou que os signos são meios auxiliares para a solução de tarefas psicológicas. Analogamente às ferramentas ou instrumentos técnicos de trabalho, exigem adaptação do comportamento a eles, do que resulta a transformação psíquica estrutural que promovem.

Assim concebido, o real significado do signo na conduta humana só pode ser encontrado na função instrumental que assume. Enquanto o instrumento técnico se interpõe entre a atividade humana e o objeto externo, o psicológico se orienta em direção ao psiquismo, de sorte que os primeiros transformam o objeto externo, os segundos transformam o próprio sujeito. Não obstante suas especificidades funcionais, ambos, instrumentos técnicos e signos, se incluem num conceito mais geral de atividade mediada, ou seja, um tipo de atividade na qual se impõe uma influência recíproca entre sujeito e objeto, da qual depende a própria consecução das finalidades da ação.

O conceito de mediação ultrapassa a relação aparente entre coisas, penetrando na esfera das intervinculações entre as propriedades essenciais das coisas. Daí que, para Vigotski, a interiorização de signos - ou emprego de "ferramentas" psíquicas - se revele matricial na defesa da tese acerca da natureza social do psiquismo humano, uma vez que a referida interiorização sintetiza, "condensa" a sociedade que comporta os signos, o ser social que os porta por interiorização e que, na condição de outro, medeia a inserção social de cada indivíduo particular, bem como a decorrente transformação que essa interiorização provoca em suas ações.

Destaque-se, pois, que ao introduzir o conceito de mediação Vigotski não o tomou como simples "elo" entre coisas, como muitas vezes interpretado por leitores não marxistas. Para ele, a mediação é interposição que provoca transformações, encerra intencionalidade socialmente construída e promove desenvolvimento, enfim, uma condição externa que, internalizada, potencializa o ato de trabalho, seja ele "prático" ou "teórico".

Nessa proposição radica, para a psicologia histórico-cultural, a concepção de educação escolar, que, ao promover - pela mediação do ensino - a interiorização dos signos da cultura, modifica radicalmente o desenvolvimento e a estrutura das funções psíquicas, reconstituindo suas propriedades e possibilitando-lhes o mais amplo alcance. Eis, pois, o nexo psicológico real entre a qualidade da transmissão de conhecimentos promovida pela educação escolar e a formação psíquica dos indivíduos, dado que afirma a unidade entre as proposições dessa teoria e da pedagogia histórico-crítica. Procuraremos ilustrar essa unidade, mais detidamente, no último item deste texto. Antes, porém, cumprenos alguns esclarecimentos acerca da proposição do psiquismo como sistema interfuncional.

\section{O psiquismo como sistema interfuncional}

Conforme exposto, é por meio da atividade vital humana, do trabalho, que os homens se relacionam com a natureza tendo em vista satisfazer suas necessidades, no que se incluem aquelas criadas nesse mesmo processo. E é justamente para melhor captar e dominar a natureza que os processos mentais se complexificam, originando um psiquismo altamente sofisticado. Assim, a inteligibilidade acerca dos fenômenos da realidade é, ao 
mesmo tempo, produto do desenvolvimento histórico da atividade humana e condição para sua efetivação.

Foi levando em conta essa premissa marxista que Vygotski (1995) buscou os primeiros elementos para afirmar a natureza social do psiquismo humano, definindo-o como um sistema interfuncional e caracterizando-o no processo de superação de seus constituintes naturais, elementares, em direção à conquista de novas propriedades, instituídas pela apropriação dos signos da cultura e denominadas como funções psíquicas superiores.

O psiquismo como sistema interfuncional abarca os processos funcionais sensação, percepção, atenção, memória, linguagem, pensamento, imaginação, emoções e sentimentos, que, como unidade de contrários, corrobora a formação da imagem subjetiva da realidade objetiva. Pelos limites impostos a este texto, apresentaremos uma brevíssima caracterização dos referidos processos.

A sensação é a mais primitiva das funções, graças à qual as propriedades isoladas dos estímulos são captadas por ação do substrato neurofisiológico denominado "analisadores". Tais propriedades são, então, unificadas por meio da percepção, a quem compete a formação da imagem totalizadora do objeto.

Da íntima relação existente entre essas duas funções resulta, muitas vezes, a indistinção entre suas especificidades, dado que demanda o destaque ao grau distintivo de complexidade que as caracteriza. No momento do nascimento, os órgãos dos sentidos já possuem significativo desenvolvimento, possibilitando à criança respostas motoras, visuais, táteis, gustativas, olfativas, interoceptivas e proprioceptivas. No entanto, essas respostas assentam-se nos reflexos incondicionados e, apenas gradativamente, adquirem nova natureza, qual seja, reflexo condicionada.

As percepções, por sua vez, desenvolvem-se nesse trânsito, à medida que os reflexos incondicionados vão cedendo lugar aos reflexos condicionados e, posteriormente, às aprendizagens sociais mediadas pela linguagem. São resultados da estimulação complexa, ou seja, de articulações e integrações entre diversas sensações, promovidas pela maturação do sistema nervoso central e, sobretudo, pela exposição a distintos estímulos sensoriais.

Todavia, o indivíduo vive permanentemente exposto a uma miríade de estímulos perceptuais, de tal forma que a captação de todos eles seria absolutamente impeditiva à organização do comportamento com vista a um fim específico, do que resulta o desenvolvimento da atenção. Graças à atenção pode ser construída a imagem de uma figura em relação a um fundo. Por essa via, determinados influxos percebidos são selecionados e seus concorrentes inibidos possibilitando, assim, a concentração em um conteúdo específico ou em um foco atencional.

Ocorre, porém, que a experiência humana também seria comprometida se as imagens sobre as quais incide a concentração desaparecessem sem deixar vestígios. Por consequência, urge a memória, a quem cumpre a formação de imagem por evocação daquilo que no passado foi sentido, percebido e atentado - ou por outra, a quem compete a fixação, o armazenamento e evocação das experiências. Se do ponto de partida a atenção e a memória despontam subjugadas às suas bases naturais, orgânicas, manifestando-se de modo involuntário, ao longo do desenvolvimento cultural suplantam essa condição, adquirindo possibilidades de expressão complexa, isto é, voluntária.

Sensação, percepção, atenção e memória, mesmo em suas formas elementares, atuam diretamente na formação de imagens psíquicas, condição tanto para os animais quanto para os homens à orientação na realidade. Contudo, do processo ontogenético pelo qual o homem se diferencia essencialmente dos demais animais decorre uma conquista 
ímpar: a conversão das imagens psíquicas em signos e a construção do sistema de signos denominado linguagem.

Graças ao desenvolvimento da linguagem e, consequentemente, da atividade mediada pelos signos, o homem supera os limites da representação sensorial imediata da realidade, própria também aos animais, passando a representá-la por meio de palavras. Essa superação aponta na direção da construção de ideias, que são, a rigor, os conteúdos do pensamento. As ações mediadas por signos despontam, assim, como propulsoras de novos arranjos interfuncionais, requalificando a totalidade do funcionamento psíquico.

Cabe observar que, embora evidente a interconexão entre pensamento e linguagem, em suas origens, eles não coincidem. A finalidade primária da linguagem é servir de meio de comunicação enquanto a finalidade do pensamento é o conhecimento e a regulação do comportamento. O nexo entre eles, sistematicamente explicado por Vygotski (2001), ocorre no transcurso do desenvolvimento, na medida em que a comunicação passa a demandar o pensamento e ele, a se manifestar por meio da linguagem. Nesse transcurso, a linguagem torna-se "linguagem intelectual" e o pensamento converte-se em "pensamento verbal".

Destarte, verifica-se no desenvolvimento das funções psicológicas um trânsito de superação contínua que implica: atividade - captação do real - imagem - signo = palavra ideia. As ideias manifestam-se como conceitos e/ou juízos. Não obstante a íntima relação existente entre conceitos e juízos, é importante destacar que os primeiros refletem as características gerais, essenciais e distintivas dos objetos e fenômenos da realidade, sintetizando propriedades que conferem especificidade ao objeto ou fenômeno. Os segundos compreendem os conteúdos dos conceitos, produzindo-se no estabelecimento de conexões e relações entre os objetos conceitualmente representados. Pelos objetivos desse texto, dedicaremos uma atenção especial à função pensamento.

No que tange ao desenvolvimento do pensamento, consubstanciado na formação dos conceitos e juízos, é importante, primeiramente, observar que a origem das idéias é a atividade prática do homem na realidade concreta, objetiva. Assim, o pensamento surge na base do reconhecimento sensorial e o excede amplamente, graças ao desenvolvimento da linguagem e das operações lógicas do raciocínio, isto é, da análise/síntese, comparação, generalização e abstração. Apenas gradativa e paulatinamente é que ele vai independendo das ações de natureza prática e afirmando-se como atividade teórica. Entretanto, cabe afirmar que essa independência será sempre relativa, uma vez que a prática do conjunto dos homens jamais deixará de ser a base e o critério de exatidão do pensamento, posto que essa exatidão se impõe como mediação decisiva na relação sujeito-objeto.

Vygotski (1996, p. 71) dedicou-se rigorosamente à análise do processo de formação de conceitos, estabelecendo uma decisiva distinção entre conceitos espontâneos, constituídos na experiência prática e assistemática cotidiana e os conceitos científicos, elaborados e objetivados sistematicamente pelo trabalho intelectual da humanidade e transmitidos às novas gerações por meio de processos educativos, especialmente, na sociedade moderna, pela educação escolar. Aos primeiros denominou como "equivalentes funcionais dos conceitos" ou "conceitos potenciais" e aos segundos como "verdadeiros conceitos" ou "conceitos propriamente ditos".

Segundo esse autor, a formação do pensamento conceitual compreende um longo e complexo processo de construção de abstrações, elaboradas por meio de generalizações advindas da análise dos atributos dos objetos representados pelos conceitos potenciais. Esse processo se estende até a adolescência, quando o pensamento alcança as possibilidades para operar por meio dos conceitos propriamente ditos, isto é, atinge seu mais alto grau de abstração. 
Alcançando esse patamar de desenvolvimento, junto ao qual operam todas as funções psíquicas, o pensamento por conceitos torna-se o guia das transformações mais decisivas do psiquismo e, por conseguinte, da personalidade do indivíduo. Todavia, o autor destaca reiteradamente o altíssimo grau de dependência desse processo em relação às condições objetivas de vida e educação, isto é, à apropriação dos produtos culturais simbólicos, diferenciando, inclusive, o papel da formação de conceitos espontâneos e dos conceitos científicos no referido desenvolvimento.

No tratamento que dispensou à formação de conceitos, Vigotski foi claro ao afirmar a superioridade dos "verdadeiros conceitos" sobre os conceitos espontâneos, privilegiando, consequentemente, a educação escolar dos conteúdos científicos. Postulou que os conceitos não espontâneos correspondem a um tipo superior de conceitos, tanto em relação ao plano teórico quanto em relação ao plano prático, formulando-se no pensamento por meio de tensões, de tarefas e atividades que exijam a atividade "teórica", as abstrações do pensamento.

Ademais, ao postular a referida superioridade dos conceitos não espontâneos, o autor levantou outra questão: os conceitos científicos se manifestam em uma esfera subjugada à orientação conscientemente dirigida, à voluntariedade, esfera que se mostra extremamente frágil na adoção dos conceitos cotidianos, orientados fundamentalmente por sua aplicação imediata e pragmática. O caráter consciente e volitivo da formação dos conceitos científicos, propriedades insuficientemente mobilizadas pelos conceitos espontâneos, institui-se, segundo Vigotski, na completa dependência da participação do pensamento complexo de um "outro", isto é, daquele que instrui e dirige a referida formação.

A elaboração dos conceitos científicos pressupõe a suplantação dos conceitos espontâneos à medida que os inserem em relações mais amplas e abstratas, em outra estrutura de generalização, em decorrência da qual a realidade pode ser refletida mais profundamente pelo pensamento. $\mathrm{O}$ desenvolvimento dos conceitos científicos corresponde, logo, às transformações das operações lógicas do raciocínio, especialmente das estruturas de generalização e abstração.

Em suma, o pensamento é um processo funcional que visa ao estabelecimento de conexões mentais entre os dados captados da realidade. Sua gênese radica no tratamento objetivo da realidade, quando as formas sensoriais de relação com ela se revelam insuficientes na superação dos desafios e tarefas que se apresentam ao indivíduo. Dessa maneira, o pensamento aparece, desde as suas origens, produzido pela atividade humana, pela evolução dos meios que a amparam - e nisso se incluem os instrumentos psíquicos, os signos, os conceitos.

Por certo, esse processo atende a um longo percurso de formação, mas apenas ele torna possível a superação das formas pragmáticas de pensamento circunscritas à "inteligência prática", operacional, em direção ao pensamento apto a captar o real para além de suas aparências fenomênicas - dado que, na ausência do pensamento abstrato mediado pelos verdadeiros conceitos não se realiza. Às propriedades do pensamento conceitual competem os domínios da criação, o que o torna a forma mais desenvolvida de pensamento já consolidada pela humanidade e, da mesma forma, expressão da universalidade teórico-prática dos homens. Ao pensamento teórico, ou conceitual, une-se outra função psicológica: a imaginação.

A imaginação, que é uma função tão complexa quanto o pensamento, se expressa na construção antecipada da imagem do produto a ser alcançado pela atividade. Graças a ela, o homem pode criar modelos psíquicos do produto final de uma atividade futura bem como selecionar os meios pelos quais possa realizá-la. Por essa via, aperfeiçoa sua capacidade 
para proposição e resolução de problemas e, consequentemente, para a transformação criativa da realidade.

Tanto quanto o pensamento, a imaginação possui caráter analítico-sintético. $\mathrm{Na}$ transformação de representações já construídas, condição para a imaginação, a análise opera desagregando elementos da imagem existente visando uma nova combinação, que, por sua vez, determina nova síntese. Portanto, a origem objetiva da imaginação é a representação da realidade concreta e seu curso pressupõe a ruptura de conexões habituais entre dado objeto e dada imagem, tendo em vista novas conexões, novo objeto, nova imagem - e assim sucessivamente.

Até o presente momento, procuramos apresentar as características gerais das funções psicológicas sensação, percepção, atenção, memória, linguagem, pensamento e imaginação, a quem compete, fundamentalmente, a construção da imagem subjetiva da realidade concreta, isto é, a construção do conhecimento objetivo. Tais funções são, via de regra, categorizadas como funções cognitivas.

Porém, a realidade concreta afeta o sujeito do conhecimento, isto é, suscita vivências ao mesmo tempo cognitivas e afetivas, ou seja, mobiliza emoções e sentimentos. As funções cognitivas possibilitam a construção do reflexo psíquico (imagem subjetiva) dos objetos e fenômenos reais que, como tal, devem ser representados. Nessa direção, o produto delas deve ser, sempre, supraindividual.

Diferentemente, as emoções e sentimentos se produzem na relação particular do indivíduo com o mundo circundante, na medida em que os objetos e fenômenos correspondem, ou não, às suas necessidades e exigências sociais que visam atender. Portanto, as respostas afetivas são idiossincráticas, não obstante as semelhanças que, aparentemente, possa haver entre as respostas de diferentes pessoas.

As emoções surgem da atividade cerebral segundo transformações registradas a partir do mundo exterior. Expressam-se como reflexo sensorial direto, como reação a qualidades isoladas dos objetos, cumprindo a função de sinalização interna para a orientação da atividade do indivíduo. Mobilizam mecanismos fisiológicos e possuem um caráter intenso, porém, circunstancial. Enquanto as emoções animais permaneceram subjugadas biologicamente, as emoções humanas adquiriram caráter social ao imbricaremse aos sentimentos.

Os sentimentos desenvolvem-se influenciados pela cultura, quando as reações emocionais, sob decisiva influência da linguagem, conquistam significações expressandose por meio de conceitos. Dependendo de propriedades dos objetos e fenômenos em conjunto, e não de propriedades isoladas deles, os sentimentos mobilizando-se por relações entre realidade presente, experiências passadas e expectativas futuras. Sua expressão é mais prolongada e constante, obedecendo a uma dinâmica figura/fundo, ao contrário das emoções, que são sempre figuras. Graças às expressões das emoções e sentimentos, as imagens construídas por meio das funções cognitivas - como posto, supraindividuais adquirem também um caráter pessoal particular.

Diante do exposto, esperamos ter demonstrado, ainda que em linhas bastante gerais, a artificialidade de qualquer cisão entre as funções cognitivas e afetivas uma vez que umbilicalmente unidas caracterizam o psiquismo humano e se colocam a serviço da inteligibilidade do real. Tais considerações nos conduzem à última questão desta exposição, na qual apresentaremos relações mais diretas entre o desenvolvimento psíquico e a educação escolar. 


\section{A educação escolar e o desenvolvimento psíquico}

Ao afirmar a natureza social do psiquismo humano, a psicologia histórica cultural evidencia o grau de condicionabilidade existente entre sua formação e os processos educativos, sobretudo ao explicitar como lei geral do desenvolvimento psíquico a dialética entre os processos interpessoais (interpsíquicos) e os processos intrapessoais (intrapsíquicos).

No que tange especificamente à formação e complexificação dos processos funcionais, há que se reconhecer que desde a sensação, que representa o mecanismo primário por meio do qual se estabelece a relação com o meio, não é o substrato natural por si mesmo que condiciona o seu desenvolvimento. Ainda que do ponto de partida sua base seja realmente natural, orgânica, o grau de dependência da sensação a ela é apenas relativo, uma vez que o próprio funcionamento e desenvolvimento dos analisadores dependem, sobretudo, dos estímulos do ambiente aos quais respondem.

A existência de uma vasta gama de estímulos atuando sobre os órgãos dos sentidos se impõe como condição indispensável ao desenvolvimento sensorial, de tal forma que desde a mais tenra idade as operações e ações da criança podem e devem ancorar-se no universo da cultura sensorial. Da mesma forma, o desenvolvimento da percepção subordina-se aos vínculos com a realidade e, fundamentalmente, às mediações culturais. A comunicação com o adulto, que dá a conhecer o mundo à criança - destacando a multiplicidade de signos que o constituem ensinando-a a atuar com eles e por meio deles -, é que induz a superação de suas formas elementares em direção ao desenvolvimento da percepção propriamente humana.

Nessa direção, o ensino escolar, à medida da natureza das ações realizadas, alia-se às condições objetivas de desenvolvimento dessas funções. As exigências fundamentais de observação, a atividade dirigida com vista à consecução de dado objetivo, a apreensão sistemática e detalhada de objetos e fenômenos, a comparação, generalização, abstração são, dentre outros, alguns dos aspectos que vinculam o ensino sistematizado e à captação sensório-perceptual.

As exigências impostas a essa captação, por sua vez, requerem a atenção, cujo desenvolvimento, isto é, superação da centralidade involuntária em direção à voluntária, depende completamente das ações realizadas. Todavia, para essa superação, a natureza das referidas ações não é variável de menor importância. As características da instrução escolar em relação ao desenvolvimento da atenção pressupõem tarefas que mobilizem o seu controle, ou seja, que determinem a atenção para além do interesse imediato, circunstancial e involuntário. A criança precisa aprender a prestar atenção e acostumar-se a fazê-lo!

A atenção superior, voluntária, forma-se necessariamente sob condições de ensino. Para tanto, é necessário oportunizar ao indivíduo, desde os primeiros anos de vida, a apropriação do conhecimento acerca do mundo que o rodeia, organizando sua percepção sobre ele e dirigindo sua atenção, tendo em vista a análise, a discriminação, a síntese, enfim, ativando formas de pensamento nas quais a atenção corrobora a identificação do essencial, do fundamental - o que vai além do mais atrativo e aparente. Ademais, a atenção voluntária é, antes de tudo, uma atenção organizada, sistemática e conscientemente dirigida para fins específicos - por conseguinte, depende do caráter das ações que se há de realizar.

Portanto, não é em detrimento de ações organizadas e dirigidas, a princípio por processos interpsíquicos, que a atenção voluntária se instituirá intrapsiquicamente. Colocar o desenvolvimento da atenção voluntária como tarefa da educação escolar implica sabê-la dependente da realização de uma vasta gama de atividades que a coloquem como requisito. O que se põe em pauta é que a formação da atenção voluntária, da memória lógica, enfim, 
de todos os processos funcionais superiores, se realiza "de fora para dentro", o que quer dizer, se originam e se estruturam por demandas da vida social. A princípio, seu desenvolvimento compreende operações forçosamente externas realizadas sob orientação do outro e, a esse serviço, se impõe o ensino escolar que de fato visa à superação do funcionamento elementar, primitivo.

As mudanças que possibilitam a passagem tanto da atenção quanto da memória involuntárias para voluntárias pressupõem um trânsito marcado pela interveniência da atenção e memória voluntárias externas, na base da qual todo funcionamento superior se estrutura. O controle desses processos do ponto de partida é exógeno, dependente de ações e operações sociais a partir das quais o autocontrole das mesmas pode ser conquistado. Por isso, consideramos que o adulto (no caso, o professor) "cede de empréstimo" o desenvolvimento de seu psiquismo aos seus alunos.

A memória, por sua vez, é o ponto de apoio primário do pensamento, haja vista que, nos primórdios do desenvolvimento, "pensar é recordar". Contudo, há que se diferenciar a memorização natural, mecânica e involuntária, e a memorização culturalmente formada, isto é, a memória histórica. Se a primeira assegura o registro espontâneo de episódios casuais e isolados, graças a segunda o ato de memorização se transforma em um processo volitivo, condição para que se alie a outros processos superiores - a exemplo da linguagem, pensamento, imaginação, sentimentos etc.

Pela apropriação de signos, a memorização voluntária se institui, superando a memorização mecânica, associativa, adquirindo assim suas propriedades fundamentais torna-se memória lógica e mediada. Porém, a mudança do caráter retentivo não é natural, mas depende das modificações das atividades realizadas pelo indivíduo. Destarte, o ensino escolar, como um tipo de atividade específica, dirigida e não cotidiana, desempenha um papel primordial na formação da dimensão retentiva voluntária.

A complexificação mnêmica sofre decisiva influência do desenvolvimento do pensamento, de quem depende o incremento da memória lógica e o aumento da eficácia de toda memorização e, igualmente, da linguagem, posto que graças aos signos, representados sobretudo pela palavra, as conexões interfuncionais e o grau de sistematização com o qual operam se ampliam imensamente. Operando sobre tais processos funcionais, a atividade escolar promove modificações na organização de todo sistema funcional, convertendo-o em premissa e ao mesmo tempo resultado da aprendizagem.

Contudo, para que o ensino escolar atue como influência positiva na formação e complexificação do psiquismo, há que se instituir à base de características que se proponham a tanto. Entre tais características destacamos, fundamentalmente, sua própria organização e sistematização lógica, a promoção do estabelecimento de relações e conexões internas entre os objetos e fenômenos da realidade, mediando a captação dos mesmos por conceitos lógicos e, sobretudo, pelo domínio dos significados concretos a eles vinculados. Assim, a própria racionalidade organizativa do trabalho pedagógico se apresenta como esteio do desenvolvimento de todos os processos funcionais. Nesse sentido, tal como postulado por Vygotski (1995), se as formas primárias de manifestação psíquica resultam "do cérebro", as formas superiores, complexas, resultam da apropriação da cultura.

Do mesmo modo que as demais funções, a linguagem se desenvolve sob absoluta dependência da ação do outro, embora sua radicalidade social confira à sua formação um cunho enganoso e aparentemente natural. Nesse sentido, a primeira exigência é sabê-la um processo funcional, altamente complexo, que em muito supera a mera "capacidade para falar". É na base desse reconhecimento que se pode identificar o quanto seu pleno exercício condiciona-se à qualidade do ensino a que se submete. 
Se por meios espontâneos a criança aprende a falar, apenas por procedimentos específicos de ensino pode reorganizar essa capacidade, apreendendo os elementos da linguagem e sua utilização tanto no discurso coordenado quanto na própria organização do pensamento. O domínio da linguagem se realiza, pois, no processo ativo que vai além da assimilação do material fonético, da aprendizagem e domínio do aparato verbal e do entendimento geral e superficial da língua.

Ao se colocar o ensino escolar a serviço do desenvolvimento da linguagem, há que se destacar seu papel no desenvolvimento dos domínios fonéticos, semânticos, gramaticais e, sobretudo, cognitivos. Como tal, ele deve incidir sobre a atividade linguística, isto é, sobre o processo de utilização da linguagem como "instrumento" de transmissão e assimilação da experiência humana, como veículo de intercâmbio interpessoal e como recurso imprescindível ao planejamento e controle das próprias ações.

Ademais, se o ensino escolar corrobora a formação e desenvolvimento de todos os processos funcionais, desponta como condição imprescindível ao desenvolvimento do pensamento. Potencializar o alcance possível do longo e delicado processo de formação de conceitos é, a nosso juízo, o ápice da educação escolar, na medida em que é essa formação que proporciona ao indivíduo o verdadeiro conhecimento da realidade. Como resultado dos domínios do pensamento por conceitos e, particularmente, dos conceitos científicos, é que a dinâmica do mundo objetivo refletida sob a forma de dinâmica de juízos se institui como conteúdo da consciência, balizando não apenas a compreensão da realidade, mas, acima de tudo, a concepção construída sobre ela.

À educação escolar compete corroborar o desenvolvimento do pensamento teórico, uma vez que o conceito, na exata acepção do termo, eleva a mera vivência à condição de saber sobre o vivido, isto é, permite avançar da experiência em si ao entendimento daquilo que a sustenta - condição imprescindível para as ações intencionais. Cabe destacar, ainda, que a formação de conceitos ultrapassa a esfera dos conceitos espontâneos, cotidianos, subordinando a si as transformações mais decisivas da percepção, da atenção, da memória e das demais funções à medida da ampliação dos domínios sobre os signos culturais.

Essas transformações não se identificam com um conjunto de modificações isoladas de cada função, mas com a transformação do sistema psíquico, à raiz da qual todas as funções se intelectualizam e passam a ser regidas pelo pensamento conceitual. Portanto, uma educação escolar que vise à formação de indivíduos livres carece primar pelo desenvolvimento do pensamento complexo, superior, na ausência do qual resulta comprometido o ato volitivo e, igualmente, o autocontrole da conduta.

É ainda no âmbito das diversas conexões funcionais que a formação de conceitos condiciona a formação da imaginação e também das vivências afetivas. Superada a ideia da imaginação e da criatividade como expressões naturais e livres da consciência, há que se reconhecer que apenas a liberdade interna do pensamento, do conhecimento e da ação, alcançada tão somente pela formação dos conceitos, possibilita-lhes existir objetivamente.

Ademais, como extensão das concepções naturalizantes, a imaginação e a fantasia despontam unilateralmente associadas à vida emocional em detrimento de seus vínculos cognitivos. Nessa direção, o "bom ensino" seria aquele que delega a imaginação aos estados subjetivos de ânimo, o que quer dizer, à sua própria sorte. Contrapondo-se radicalmente a essa interpretação, Vygotski (2003) foi claro ao afirmar que se ao desenvolvimento psíquico corresponde a intelectualização de todas as funções, o mesmo ocorre com a imaginação, de sorte que esse processo é tão presente e necessário na poesia quanto na geometria! Portanto, a imaginação, a criatividade, a fantasia e os próprios sentimentos não são "entes autônomos", independentes de todo o sistema psíquico. Pelo 
contrário, seu desenvolvimento resulta e se vincula, sobretudo, à formação do pensamento abstrato, isto é, a um alto grau de desenvolvimento conceitual.

Com isso, colocamos em pauta a impossibilidade de, no âmbito da educação escolar direcionada à formação de conceitos científicos, quaisquer contraposições entre objetividade e subjetividade, entre razão e emoção. Tais cisões têm comprometido sobremaneira a educação escolar em sua tarefa de corroborar a formação do indivíduo em sua totalidade real, alimentando equívocos no tratamento dispensado ao desenvolvimento psíquico. Dentre tais equívocos, destacamos as críticas que incidem sobre o ensino escolar que valoriza a racionalidade e que postulam que, por isso, ele estaria desconsiderando as outras dimensões da personalidade humana. Por esse caminho, essas posições conduzem não apenas à desvalorização dos aspectos cognitivos e dos próprios conteúdos escolares, como também ao próprio empobrecimento da vida afetiva dos indivíduos.

A educação escolar aqui referida é um processo que interfere diretamente na formação multilateral dos educandos, ciente de que os conteúdos dos próprios sentimentos não são outra coisa, senão, conceitos (VYGOTSKI, 2001). Na mesma medida, ciente também de que os conteúdos escolares mobilizadores dos pensamentos incluem "sentimentos intelectuais", isto é, os sentimentos gerados pela atividade mental requerida na construção do conhecimento. Trata-se, portanto, de uma educação escolar apta à formação e promoção de sentimentos intelectuais positivos, imprescindíveis tanto na atividade de quem aprende quanto de quem ensina.

A afirmação da educação escolar a serviço do desenvolvimento afetivo pressupõe o trabalho pedagógico como atividade interpessoal mediada por conhecimentos historicamente sistematizados, pela transmissão desses conhecimentos e por sentimentos intelectuais positivos. Considerando-se a natureza social dos sentimentos, os mesmos não emergem espontaneamente e, como todas as vivências afetivas, são engendrados pelo experienciado.

Haja vista a própria dimensão sistêmica do psiquismo, o percurso intencional que a formação de conceitos científicos atende, exigindo o domínio da própria conduta, interpõese também na construção de mecanismos necessários à contenção ou educação das respostas emocionais reflexas. Há que se destacar que o autodomínio do comportamento não se identifica com o livre atendimento de vontades individuais imediatas, mas com o autodomínio conscientemente orientado por finalidades humanizadoras, isto é, identificado com a fruição de funções psíquicas superiores.

Essas breves considerações pontuais que colocaram em pauta algumas das possibilidades desenvolvimentistas da educação escolar em face dos processos funcionais requerem duas observações. A primeira diz respeito à impropriedade do estabelecimento de correspondências lineares entre ações pedagógicas e funções psíquicas "isoladas", posto que isso representaria mais um tipo de "psicologismo" no campo da educação escolar. Ou seja, do ponto de vista pedagógico, não se trata do planejamento de ações que visem ora o desenvolvimento de dada função ora de outra - uma vez que as mesmas operam em unidade, orquestrando a atividade em curso. Trata-se, sim, da promoção de atividades ricas em possibilidades de apropriação das objetivações humanas em suas formas mais elaboradas, mais complexas, e que por isso requerem a mediação do ensino, dado que nos conduz à segunda observação.

Se é fato que a educação escolar promove desenvolvimento, também é fato que o desenvolvimento não resulta de qualquer modelo de educação escolar. Conforme procuramos demonstrar, o ensino que se volta aos objetivos desenvolvimentistas não é aquele que reproduz na escola os saberes de senso comum, marcados pela heterogeneidade da vida cotidiana, pelo espontaneísmo, pelo imediatismo e por ações assistemáticas; 
também não é aquele que esvazia a educação escolar dos conteúdos clássicos, dos conteúdos científicos em nome de "conteúdos práticos" e de conceitos espontâneos, operando nos limites dos pseudoconceitos. Igualmente, não é aquele que atribui as possibilidades da aprendizagem às particularidades individuais dos alunos tal como dadas em suas expressões empíricas, mantendo-os reféns do que são em detrimento daquilo que podem vir a ser.

Diante do exposto, podemos constatar que a pedagogia histórico-crítica, ao propor como tarefa precípua da educação escolar a humanização de cada indivíduo particular por meio da apropriação do patrimônio cultural humano genérico, ao fazer a defesa radical da transmissão dos "verdadeiros conceitos", isto é, dos conceitos científicos, encontra o mais absoluto eco na psicologia objetiva representada pela psicologia histórico-cultural, que toma por objeto não a mera aparência do psiquismo humano, mas suas possibilidades máximas de expressão e, sobretudo, as condições sociais às quais esse desenvolvimento se subordina.

É na qualidade de condição social de desenvolvimento que se erige a educação escolar tanto para Vygotski (1995; 1997; 2001) quanto para Saviani (2000; 2003; 2008), que, ao tomarem a inteligibilidade acerca do real como objetivo na formação dos indivíduos, evidenciam o papel ineliminável da educação escolar em sua consecução. Vigotski, ao afirmar a apropriação de signos como condição de superação do lastro psíquico natural em direção à conquista dos comportamentos complexos culturalmente formados coloca no centro dos mesmos o pensamento abstrato, o pensamento por conceitos, cuja formação depende, rigorosamente, de transmissão intencionalmente projetada a esse fim. Saviani (2003, p. 13), por seu turno, edifica a pedagogia históricocrítica nessa mesma direção, postulando que:

o objeto da educação escolar diz respeito, por um lado, à identificação dos elementos culturais que precisam ser assimilados pelos indivíduos da espécie humana para que se tornem humanos e, de outro lado e concomitantemente, à descoberta das formas mais adequadas para atingir esse objetivo.

Portanto, consideramos que a apropriação de signos está para a psicologia históricocultural tanto quanto o ensino dos conteúdos científicos está para a pedagogia históricocrítica, naquilo em que ambos se identificam no que tange à humanização do psiquismo, cuja manifestação objetiva se revela no grau de consciência alcançado por cada indivíduo.

\section{Considerações finais}

A pedagogia histórico-crítica, ao asseverar a escola como lócus do saber historicamente sistematizado e espaço privilegiado para a socialização desse saber a coloca na condição de uma instituição social que deva prezar pela transmissão de conhecimentos que incidam sobre o desenvolvimento dos indivíduos e sobre as contradições sociais por eles enfrentadas, posicionando-se a favor de determinadas possibilidades - em especial da plena formação humana - e contra outras, a exemplo da conversão dos saberes clássicos em propriedade privada da classe dominante (SAVIANI, 2000; 2003; 2008).

A afirmação da potencialidade desenvolvimentista e equalizadora dos conhecimentos que devam caracterizar a educação escolar reside no cerne da pedagogia histórico-crítica e também da psicologia histórico cultural, determinando a radical oposição à secundarização do ensino dos conhecimentos sistematizados historicamente e consolidados pela prática social da humanidade. O estofo materialista dessas teorias aponta 
a apropriação do patrimônio cultural como "ferramenta" imprescindível à existência ativa dos indivíduos, posto que a captação imediata da realidade não assegura por si mesma o seu real conhecimento, ainda que dela resulte inúmeros mecanismos adaptativos. Apenas como resultado das complexas mediações do pensamento é que o objeto da captação tornase inteligível e, assim sendo, é enquanto abstração mediadora na análise do real que o ensino da filosofia, da ciência, da arte, etc., adquire sua máxima relevância.

A ênfase na transmissão dos conhecimentos clássicos, tal como postulado pela pedagogia histórico-crítica, não perde de vista que a teoria, por si mesma, não transforma a realidade. Mas também não perde de vista que essa transformação exige a formação de indivíduos aptos a fazê-lo. Se, por um lado, a construção do conhecimento está diretamente ligada à atividade, esta, por si mesma, não é suficiente para engendrar a formação daquele. A atividade cognoscitiva e teleológica requer o registro e conservação das objetivações históricas e, ao mesmo tempo, a comunicação educativa entre os homens, pelos quais se realizam as apropriações de tais objetivações. Ou seja, demanda condições sociais de transmissão, demanda ensino, demanda uma sólida educação escolar!

Nessa direção, sem preterir que no interior da escola se impõem as contradições inerentes à sociedade de classes, ou seja, sem preterir que as contradições da sociedade burguesa atravessam o trabalho pedagógico - análise que também se destaca na pedagogia histórico-crítica - há que se reconhecer que a desqualificação do ensino de conceitos científicos se coloca a serviço da obnubilação da consciência dos indivíduos, posto mantêla refém da aparência dos fenômenos, da empiria e das circunstâncias efêmeras sensorialmente captadas, ou por outra, posto manter os indivíduos no limiar do desenvolvimento de suas funções psíquicas superiores.

Nesse sentido, julgamos que posições depreciativas das possibilidades de a educação escolar contribuir para a superação desse modelo de sociedade preterem que a formação psíquica dos indivíduos também se institui como uma das condições para a referida superação. Portanto, se a compreensão marxiana e marxista dos fenômenos naturais e sociais demanda sabê-los sínteses de múltiplas determinações, há que se reconhecer na apropriação dos signos da cultura uma das determinações da formação psíquica e essa formação, por sua vez, também como um dos fatores determinantes para outro projeto de sociedade.

\section{Referências}

LEONTIEV, A. N. Desenvolvimento do psiquismo. Lisboa: Livros Horizonte, 1978.

SAVIANI, D. Escola e Democracia. 40. ed. Campinas: Autores Associados, 2008 (Edição comemorativa).

. Educação: do senso comum à consciência filosófica. 13. ed. Campinas: Autores Associados, 2000.

Pedagogia histórico-crítica: primeiras aproximações. 8. ed. Campinas: Autores Associados, 2003.

VIGOTSKY, L.S. La imaginación y arte em la infancia: Ensaio psicológico. Madrid: Akal, 2003.

VYGOTSKI, L.S. Obras Escogidas. Tomo II. Madrid: Visor, 2001.

Obras Escogidas. Tomo I. Madrid: Visor, 1997.

Obras Escogidas. Tomo III. Madrid: Visor, 1995. 
Notas

${ }^{1}$ Texto elaborado originalmente para exposição na Mesa Redonda "Marxismo e Educação: Fundamentos da Pedagogia Histórico-Crítica”. VII Colóquio Internacional Marx e Engels, IFCH-UNICAMP, 2012.

2 Livre Docente em Psicologia da Educação. Professora do curso de Graduação em Psicologia da UNESP/Bauru e do Programa de Pós-Graduação em Educação Escolar da UNESP/Araraquara. Membro do Grupo de Pesquisa "Estudos Marxistas em Educação".

${ }^{3}$ Adotaremos a grafia Vigotski, exceto em citações, nas quais reproduziremos a forma presente na obra referida.

Recebido em junho-2012

Aprovado em agosto-2012 